\title{
Al "reencuentro" de las "cuestiones": un comentario sobre el estudio socio-histórico de las problematizaciones
}

\author{
To the "re-encounter" of "questions": a comment on the socio-historical study of \\ problematizations
}

\author{
Victoria Haidar \\ vickyhaidar@yahoo.com.ar \\ Centro de Investigaciones de la Facultad de Ciencias \\ Jurídicas y Sociales de la Universidad Nacional \\ del Litoral, CONICET, Argentina
}

Cita sugerida: Haidar, V. (2021). Al "reencuentro" de las "cuestiones": un comentario sobre el estudio sociohistórico de las problematizaciones. Sociohistórica, 47, e126. https://doi.org/10.24215/18521606e126
Resumen: Partiendo de la idea de que el estudio socio-histórico de las problematizaciones usa la imaginación histórica para reencontrar las cuestiones que están en la raíz de algunos de los debates del presente, el artículo procura: a) fundamentar tal afirmación y b) explicitar qué puede y suele esperarse como saldo de una investigación orientada por tal metodología. Para ello, en el apartado 1 se caracterizan los factores que configuran las situaciones que instigan a "problematizar" algo, así como las maniobras de "socialización/dispersión" y "comparación histórica” que conducen a postular una problematización. Sobre la base de un ejemplo, el apartado 2 apunta a visibilizar algunos de los elementos que guían los ejercicios de imaginación histórica de los que ello depende. Finalmente, el apartado 3 pone el foco tanto sobre el tipo de escritura de la historia al que conduce la metodología, como sobre los efectos ético-políticos con los que esta se asocia.

Palabras clave: Problematización, Imaginación histórica, Metodología.

Abstract: Starting from the idea that the socio-historical study of problematizations uses the historical imagination to rediscover the questions that are at the root of some of the debates of the present, the article tries to: a) support such an affirmation and b) explain what can and is usualley expected as the result of an investigation oriented by such methodology. To do this, section 1 characterizes the factors that configure the situations that instigate the work of "problematize" something, as well as the "socialization / dispersion" and "historical comparison" maneuvers that lead to postulate a problematization. Based on an example, section 2 aims to make visible some of the elements that guide the exercises of historical imagination on which it depends. Finally, section 3 focuses both on the type of writing of history to which the methodology leads, and on the ethical-political effects with which it is associated.

Keywords: Problematization, Historical imagination, Methodology. 
Este escrito retoma y desarrolla algunas de las ideas a partir de las cuales pretendí defender, en una mesa redonda que giraba en torno a "los usos de la historia para investigar problemas sociales", y en la que estaban representados los enfoques de la historia intelectual, la historia de los intelectuales, la historia política y cultural, la historia reciente y los estudios sobre memoria, el método de inspiración foucaultiana que guía mis investigaciones.

No era la primera vez que, ganada por un impulso misionero, me tomaba el trabajo de desmenuzar, para luego transmitir (enseñar, poner en discusión, etc.) los conceptos, presupuestos, pretensiones y operaciones de conocimiento que están implícitos en lo que, a falta de una expresión más apropiada, he optado por llamar "estudio socio-histórico de las problematizaciones". ${ }^{1} \mathrm{Y}$, aunque cada vez que lo intento me cause vértigo, tampoco debutaba en la aventura de referirme, ante una audiencia conformada por historiadores, ${ }^{2}$ al modo en que mi trabajo vampiriza el pasado con la pretensión de "eventualizar" el presente. ${ }^{3}$

Apoyándome sobre las respuestas que había dado al cuestionario ${ }^{4}$ en torno al cual giraban los intercambios, y que "relojeaba" de tanto en tanto (mientras no estaba consultando los comentarios que me habían suscitado las respuestas que las y los demás colegas habían dado a las mismas preguntas, o tomando nota de lo que la experiencia misma de la conversación arrojaba en términos de "dichos inesperados" y "cruces jugosos"), intenté explicar, en una calurosa tarde de diciembre, qué cosas se podían hacer (y qué había intentado hacer yo misma en trabajos anteriores)con las problematizaciones y qué clase de efectos, tanto de conocimiento como ético-políticos, podían esperarse de una investigación que tomara como objeto tal sinuosa categoría.

Considerando las dificultades que entraña todo ejercicio de traducción, no menos que la amistosa sordina que, movida por la intención de no interferir en la conversación, impuse a mis palabras, ${ }^{5}$ estoy segura de que estuve lejos de cumplir el objetivo que entonces me había fijado.

Ciertamente, no recuerdo cuál de las varias "entradas" del cuestionario elegí para referirme a una noción cuya mayor riqueza radica, en mi opinión, en que trabaja como se espera lo haga el jugador número cinco de un equipo de fútbol; esto es, armando juegos. Y ello, en relación tanto con las indagaciones teóricoempíricas acerca de los más variados temas al servicio de las cuales se la ha puesto a funcionar, como con las investigaciones de corte teórico que discurren sobre la obra de Foucault.

Pero, en todo caso, teniendo en vista algunas de las condiciones de producción de este escrito (el público al que apunta Sociohistórica, el cuerpo de textos que integra), he decidido focalizarme en el modo en que el trabajo con problematizaciones se sirve de la imaginación histórica para “reencontrar" "cuestiones”.

\section{PreliminaR}

La elección del primero de los dos términos entrecomillados, "reencontrar", que el mismo Foucault ${ }^{6}$ utiliza para referirse al objeto de la "historia del pensamiento", tiene dos propósitos. Por un lado, dice del carácter histórico de las problematizaciones, indica que estas existen en una "duración” y que el mismo concepto, entonces, "estabiliza" o "fija" algo. Por otro lado, transmite al propio método algo de la temporalidad "accidental", "acontecimental" en la que se produce / emerge aquello que, desde esa aproximación, funciona como "objeto". En efecto, las problematizaciones que el método procura reencontrar / reconstruir deben su emergencia a un "encuentro", reactivo pero creativo, inteligible pero en parte siempre azaroso, entre el "trabajo del pensamiento" y una "situación” determinada.

La elección del segundo término, “cuestión”, que deriva del latín quaestio, quaestionis (acción de buscar, interrogatorio, examen, indagación, averiguación), ${ }^{7}$ responde, por su parte, a la intención de marcar que aquello que, erudición y perspicacia histórica mediante se espera reencontrar tiene la forma de una "interrogación" lo "suficientemente amplia" como para enmarcar varios "grupos" o "nodos" de problemas y respuestas desarrollados a lo largo del tiempo, que reconocen distintas condiciones de producción. 
Aquí, nuevamente, resulta útil hacer dos señalamientos. El primero concierne al hecho de que aquello que se articula como objeto es una "pregunta" y no un "concepto" o un "término". Aprovechando una de las significaciones que se desprenden de su rica etimología, la elección del término “cuestión” responde al propósito de emplazar el tipo de indagación de que se trata en el dominio de lo que, tomando en préstamo una expresión de Thomas Osborne (2003), me inclino por llamar una "problematología": esto es, un estilo de investigación que asocia el desarrollo del conocimiento al estudio de "problemas" y no de "soluciones" (teorías o racionalizaciones post hoc).

El segundo refiere a la dimensión relativa a la "escala” en la que se desarrolla el estudio socio-histórico de problematizaciones; problema que en los últimos años ha sido considerado, asimismo, en el ámbito de la historia intelectual. ${ }^{8}$

Así, la "escala" que resulta "pertinente" al estudio socio-histórico de "problematizaciones" no es cualquiera. Por el contrario, la investigación debe plantearse a una escala lo suficientemente "amplia" o "extensa" como para habilitar la comparación entre algunas (sino todas) las "versiones" o "modulaciones" con las que una misma interrogación o cuestión se presenta (si se me permite la expresión) en su "existencia dispersa”. Al trazar sus historias filosóficas, Michel Foucault se midió con "grandes cuestiones", como ser la experiencia de la locura, el castigo y la sexualidad; las estudió tanto en su "larga duración" como en su dispersión "disciplinar".

Pero, como explicaremos en el apartado siguiente, una problematización también es susceptible de ser estudiada en su dispersión "geográfica" e incluso "geopolítica", teniendo en cuenta las modalidades que asume "simultáneamente" una misma pregunta en las formulaciones que de ella se realizan en distintos contextos nacionales; así, por ejemplo, en los países del Norte y del Sur.

\section{UN BAÚL LLENO DE HISTORIAS}

$\mathrm{Al}$ amparo de conceptos provenientes de la cantera foucaultiana (como genealogía, problematización, ontología del presente, historia del presente, etc.) se han escrito historias: de la cuestión social, del Estado de Bienestar, del hogar, de la pobreza, etc. Tales historias no se distinguen, paradójicamente, por la originalidad de los análisis históricos que despliegan. Por el contrario, suelen edificarse a partir de los sólidos cimientos que provee el conocimiento historiográfico disponible. Si consiguen prestigio, no es gracias al "descubrimiento" de un nuevo archivo o de la consistencia de las argumentaciones históricas que despliegan a partir de materiales ya explorados.

Más bien, como David Garland (2014, p. 376) apunta en un artículo dedicado a esclarecer las precondiciones de las afamadas genealogías foucaultianas, aquellas (y lo mismo cabe para las investigaciones que procuran recrear tal metodología) deben su eficacia a la "especificación inicial del problema" o, en otros términos, a la postulación de la problematización que constituirá la unidad del análisis socio-histórico a desplegarse.

Tratándose de aquello que singulariza al tipo de investigación socio-histórica al que me refiero en este escrito, resulta relevante esclarecer (hasta donde sea posible) las condiciones de las que depende la articulación de las preguntas que la motorizan en términos de "problematización". Desmenuzar o desglosar, con una finalidad tanto crítica como pedagógica, las operaciones implicadas en ello.

Las condiciones a las que se alude están dadas, por un lado, por la aparición de una "situación" en la que los hábitos, creencias, ideas, etc., que sostienen de un modo irreflexivo, e incluso inconsciente, todo un dominio de acción o comportamiento pierden la "familiaridad" o la "certidumbre" que lo mantenían al margen del campo de visibilidad del pensamiento (Foucault, 1999, p. 360).

Tal descripción comprende tanto la situación actual, en la que se encuentra inmersa la investigadora o el investigador, y que la o lo impulsa a investigar, como las situaciones en las que se han desarrollado, en otras 
coyunturas históricas, los "focos de problematización" que es preciso identificar para "re-problematizar" la situación presente.

$\mathrm{Al}$ caracterizar, entonces, la "situación" o "contexto" en el que tienen lugar las problematizaciones, el filósofo francés se refirió al papel "instigador” que desempeña tanto la aparición de encrucijadas, dificultades, crisis, incertidumbres, como los desplazamientos y desajustes que tales circunstancias generan en las sociedades, grupos e individuos a los que afectan. Revisando los textos, diversos, en los que el autor avanzó en el esclarecimiento de los factores que condicionan (mas no causan) la "invención" o "creación" de una problematización, surge que el mismo prestó atención a dos signos o indicadores de los procesos, muchas veces tenues, de "des-familiarización" o "des-naturalización” que las preceden: por un lado, la "tematización" de aquello que otrora se realizaba de manera silenciosa y, por otro lado, el surgimiento de sentimientos de "preocupación", "inquietud" y "ansiedad" en relación a algo.

La forma en la que Foucault presenta las situaciones críticas que detonan las problematizaciones no deja de estar matrizada por una dicotomía tal como la que rige las lecturas más convencionales del cambio histórico que él mismo combatió con ahínco. Así, en su mirada, la historia de las sociedades está escandida por pasajes del "mutismo" al "parloteo", de la "a-problematicidad" a la "problematicidad".

Leyendo a Foucault en tándem con Dewey, esto es, desde la perspectiva del pragmatismo estadounidense, autores como Koopman (2009) y Barnett (2015) observan que el énfasis sobre la temporalidad episódica de las problematizaciones conduce a perder de vista el carácter en sí "problemático" que tiene la vida social, el hecho de que la "reflexividad" es una dimensión inherente a todas las prácticas sociales.

Tal señalamiento tiene una particular significación en una sociedad periférica como la nuestra, en la que la "crisis" está lejos de ser un hecho episódico. Asimismo, cobra especial relieve en la época actual, en la que, de la mano de la aparición de nuevos riesgos globales, las situaciones de incertidumbre se multiplican y se vuelven parte de la cotidianeidad.

Así, en lugar de partir de la ficción de la "a-problematicidad", el contexto que motiva el estudio sociohistórico de problematizaciones resulta mejor descripto en términos de una intensificación o ampliación de las dificultades e incertidumbres, así como de las ansiedades y preocupaciones que jalonan la vida en las sociedades de la modernidad avanzada; contexto en el que se articulan o resultan articulables nuevas demandas de justificación.

Con el propósito de "detectar" y "profundizar" la vertiente interrogativa de intercambios, opiniones, controversias, que no crea, puesto que ya están en curso, pero que sin embargo le resultan insatisfactorios (porque se despliegan en un nivel que no supera la polémica o porque se han desarrollado en formas que bloquean el debate o que simplemente considera equivocadas), la investigadora o el investigador procederá a "yuxtaponer" y "comparar" la práctica que ha funcionado como disparadora de las opiniones, interpretaciones, que le resultan insatisfactorias, con "otras prácticas".

Esas otras prácticas con las que una y otro "vinculan”, “asocian”, el asunto en discusión reúnen una doble condición: por un lado, son diferentes pero exhiben algún parecido de familia con aquellas de la cuales se parte; es decir que nadie las pondría en la misma bolsa pero resultan comparables. Y, por otro lado, reconocen otras varias cronologías diferentes que no pueden unificarse y que no son sucesivas sino discontinuas (Haidar, 2019).

Como resultado de esa clase de maniobras de "asociación”, “dispersión” e "historización”, el "texto", la "institución” o la "teoría” (entre otras posibles prácticas) de los que parte la investigación cambia de escala, quedan inscriptos/enmarcados en la interrogación o modo de encuadre más "amplio" que lo hacen posible.

En esta forma de proceder, la imaginación histórica es el recurso que, junto con otras estrategias de dispersión, permite "reencontrar" el haz unificado de interrogantes emergente en un momento dado del pasado que, siendo reformulado varias veces, sigue vigente en la actualidad (Castel, 1997, p. 19); y frente al cual se han propuesto, a lo largo de la historia, diferentes "soluciones". 
Mediante tal clase de indagación es posible "abrir" los problemas en su "emergencia", visibilizar las relaciones (esto es, las conexiones, los encuentros, las estrategias) que dan lugar a que "algo" (una experiencia, proceso, etc.) se instituya como objeto de pensamiento y mostrar la diversidad, e incluso oposición, de las concepciones de lo que en cada una de las instancias históricas consideradas en el contexto de una investigación cuenta como solución.

$\mathrm{Al}$ referirse al modo en que una misma pregunta habilita la producción simultánea de múltiples respuestas, Foucault introduce en la discusión acerca de la significación de las problematizaciones otros dos elementos que consideramos relevante mencionar: uno está dado por el carácter "transdisciplinar" que el autor les atribuye; así, las "cuestiones" que el método incita a reencontrar atraviesan distintas disciplinas y ámbitos de debate, y pueden ser formuladas con distintos vocabularios. El otro elemento, que deducimos de la insistencia con que el autor afirma que lo que se plantea como solución puede asumir formas no sólo distintas sino “opuestas", está dado por la flexibilidad, maleabilidad o, incluso, polivalencia político-ideológica que revisten las problematizaciones.

Existen otras dos posibilidades analíticas que, si bien el filósofo francés no explora, resultan habilitadas por el tipo de aproximación "sincrónica" al que conduce la maniobra de "dispersión" que debe seguirse para identificar una problematización.

Una de ellas tiene que ver con considerar el radio de alcance de una interrogación no desde un punto de vista "temático" o "disciplinar" sino "geográfico". Desde esa perspectiva, y en sintonía con lo que una serie de autores denomina "abordaje simultáneo" (Fabian, 2014Bialakowsky, 2018), pueden reconstruirse tanto los procesos de emergencia como las transformaciones de ciertas "cuestiones” a través de distintos contextos nacionales. Una línea de dispersión de ese estilo puede conducir al trazado de genealogías “desalineadas”, para utilizar la feliz expresión con la que Ana Grondona las califica en otro de los trabajos que integran este Dossier.

La otra posibilidad analítica que Foucault omite considerar tiene que ver con aquello que, como advierte Bacchi (1999, pp.12-13, citada por Chao, 2019, p. 129), queda "desproblematizado" mediante la problematización de que se trata. En tanto mecanismos de "encuadre" (Bacchi, 2019), las problematizaciones determinan lo que se considera significativo en una coyuntura dada y lo que queda fuera de consideración. ${ }^{10}$

Además de investigar cuestiones en su emergencia, la indagación a la que nos referimos apunta a trazar retrospectivamente, es decir partiendo del presente, un "linaje de problemas". Ello abre la posibilidad de re-organizar los materiales que surgen de esa exploración de otra manera e incorporar contenidos desconsiderados.

Cuando algo del presente, que considerábamos totalmente contemporáneo y circunscripto a un espacio (territorial, disciplinar, temático) específico, resulta atrapado por la temporalidad (necesariamente de más largo alcance) e intensión, siempre más extensa, de una problematización, los debates adquieren una densidad histórica y teórica inesperada.

\section{UNA PROBLEMATIZACIÓN "EN PROCESO": EL MAKING OF DE "LA VÍA PRO COMO TERCERA VÍA"11}

Este apartado tiene como propósito ilustrar, a través de un ejemplo tomado de mis experiencias de investigación, el tipo de estrategias de "socialización” y "yuxtaposición histórica” que suelo ensayar como parte de los numerosos trabajos preliminares al "desplante" de una problematización. En el desarrollo de tales estrategias, el foco está puesto, en particular, en los elementos ("indicios", "huellas discursivas") que utilizo como guía para ejercitar el tipo de imaginación histórica que, al permitir asociar y comparar prácticas que reconocen distintas temporalidades, me coloca, metafóricamente hablando, en el camino de una problematización.

Escribí "La Vía PRO como tercera vía" entre fines de 2017 y comienzos de 2018, en una coyuntura en la que la caracterización político-ideológica de Propuesta Republicana, el partido que por entonces gobernaba 
la nación argentina, era objeto de acaloradas discusiones ${ }^{12}$ que se desarrollaron, fundamentalmente, en periódicos y revistas culturales (esto es, en medios que tienen un público más extenso y heterogéneo que el universitario), y de las que, además de periodistas, participaron cientistas sociales e intelectuales. ${ }^{13}$

Sintetizando los términos de una polémica que hoy luce anacrónica, las posiciones se dividían entre quienes enfatizaban la continuidad de PRO con los discursos y las políticas económicas y sociales de orientación neoliberal-conservadora implementadas en la Argentina en otros períodos históricos, particularmente en el transcurso de la última dictadura militar, y quienes, por el contrario, sostenían que estábamos frente a una "nueva" derecha que, además, era "democrática".

En ese contexto, en el que los binarismos "viejo/nuevo" y "democrático/autoritario" sobredeterminaban los intercambios, me interesó explorar la expresión "tercera vía”, a la que algunos de los cuadros del partido habían apelado para caracterizarlo, porque condensaba "algo" de "todo" lo que estaba en debate. En efecto, el sintagma "tercera vía” viene siendo utilizado, desde fines del siglo XIX y comienzos del XX, para designar ideas y propuestas socio-económicas y ético-políticas, por movimientos políticos, intelectuales, dirigentes políticos y expertos de muy diversa orientación, tanto democrática como autoritaria. Se trata de una fórmula que, además, está vigente en la actualidad y que ha sido objeto, en los últimos treinta años, de reelaboraciones realizadas desde perspectivas sociológicos y politológicas.

Revisando, entre otros trabajos, los escritos que uno de los autores de este Dossier dedica a esclarecer el discurso de PRO (Morresi, 2016), me llamó la atención el uso, en un documento partidario titulado "La vía PRO. Una aproximación a lo que somos" (Devoto, 2014) ${ }^{14}$, de la fórmula “tercera vía”, a la cual se apelaba como medio para construir una identidad partidaria con independencia de la figura de Mauricio Macri.

Más precisamente, lo que despertó mi curiosidad fue algo que en tal documento asumía el estatuto de un "síntoma"... ¿De qué? Del carácter siempre "fallido" (nunca totalmente logrado, siempre incompleto) que tenía PRO de ser un "partido de lo nuevo"; un partido que, seduciendo a la ciudadanía a partir de "lo novedoso" de su forma de hacer política, inscribía su propuesta en dos dimensiones temporales (presente y futuro) y elegía dejar el pasado atrás. Dicho en otros términos: sospechaba que, al decir (se) "tercera vía”, PRO traicionaba la intención de "no retroceder demasiado en el tiempo" (Devoto, 2015), para inscribirse en una familia de discursos con una extensa y enrevesada genealogía.

La fórmula de "tercera vía" fue la "evidencia" que detonó el tipo de investigación socio-histórica de la cual surgió el artículo al que aquí me refiero. Esto es, la clase de "razón”, "discurso", "argumento", "propuesta" que, siendo movilizada por propios y extraños como sinónimo de una opción contemporánea (una opción de "centro", "democrática", respetuosa de la competencia de mercado pero revestida de sensibilidad social), decidí "abrir", "desarmar", a partir de los elementos que surgían de los textos en los que tal expresión se empleaba y de otros textos a los que estos reenvían, con el propósito de inscribir el modo en que dicha expresión se había puesto a rodar en la realidad política y cultural argentina en una interrogación más general y duradera, que a lo largo del siglo XX se había articulado de distintas maneras.

Sintetizando enormemente los argumentos que desarrollo en el trabajo, a partir del año 2014 PRO comenzó a utilizar la expresión "tercera vía” como sinónimo del ideario en torno al cual aspiraba a definir su identidad partidaria (Vommaro, Morresi y Belloti, 2015). La caracterización que de dicho ideario surgía de los documentos partidarios remitía a la versión "post-ideológica" de la tercera vía que había surgido, a lo largo de la década de 1990, en el contexto de los procesos de modernización que protagonizaron las socialdemocracias europeas y, particularmente, de los debates que condujeron al Partido Popular español a auto-presentarse como un "nuevo centro político". Tal "versión" de la tercera vía, procedente de un pasado reciente, que enfatizaba la importancia del "cómo" en la toma de las decisiones políticas y reivindicaba una identidad propia para el "centro", ofrecía a PRO una serie de reflexiones, una agenda y una retórica que cuajaba con su pretensión de "renovación” de la política.

Sin embargo, más allá del objetivo, declarado, de identificarse con dicha tercera vía "post-ideológica”, había en el documento elaborado por Mauricio Devoto "huellas" que indicaban el funcionamiento de elementos 
procedentes de "otras versiones" de la tercera vía, las cuales procedían de distintas coyunturas y reconocían cronologías que no eran totalmente homologables.

Una de las huellas que en el artículo al que me refiero me ocupé de rastrear permitía vincular el discurso de PRO tanto con el programa de la "economía social de mercado" como con algunas de las reflexiones producidas desde la Segunda Guerra Mundial por los intelectuales “ordoliberales” cuyas ideas, entre otras, inspiraron las políticas que, tras la finalización de la Guerra, llevó adelante, en Alemania, Ludwig Erhard. En el documento que el otrora escribano general de la Ciudad de Buenos Aires puso en circulación en el 2014, aparecía la formulación "tanto mercado como sea posible, tanto Estado como resulte necesario", como fórmula que sintetizaba la vocación de PRO, en tanto "tercera vía”, de buscar la "complementariedad” entre el "estímulo de la iniciativa privada" y la "presencia del Estado en todos los ámbitos en que (...) [resultara] imprescindible” (Devoto, 2014, p. 10).

Enunciada por el economista y político de la socialdemocracia alemana Karl Schiller en 1953, y reiterada en el programa partidario de 1959, en el que dicha fuerza política, tras varios años de resistencia, terminó por hacer suyo el programa de la "economía social de mercado", la cita (de "segunda mano") ${ }^{15}$ de la hoy célebre frase traza un puente entre la vertiente alemana del neoliberalismo y el discurso del PRO.

Tal remisión me llevó, entonces, a reconstruir un segundo grupo de debates, que se dieron a lo largo de las décadas de 1940 y 1950 en Europa, y que no dejaron de tener resonancia en Argentina. Dichos debates giraron en torno al problema de cómo construir un orden económico que fuera socialmente sustentable. Una discusión de ese orden aparece tanto en las elaboraciones del neoliberalismo sociológico alemán como en los escritos del político alemán que es emblema de la implementación práctica de la economía social de mercado, Ludwig Erhard.

La posibilidad de ampliar aún más el registro de la tercera vía, trayendo a la discusión un tercer conjunto histórico de "preguntas y respuestas" que contribuía, asimismo, a esclarecer los términos de lo que tal expresión ponía en juego, vino de la mano de una enunciación con la que me topé en el texto Civitas Humana de Wilhem Röpke (1949, p. xiv), un intelectual ordoliberal, furibundamente anticomunista, que en 1960 visitó la Argentina invitado por el Foro de la Libre Empresa (Haidar, 2018). Röpke (1956 [1942], p. 31), que solía utilizar la expresión "tercer camino" para aludir al repertorio de propuestas políticas y culturales con las que aspiraba a superar la "estéril alternativa entre laissez faire y colectivismo", escribió lo siguiente: "un buen cristiano es un liberal que se ignora".

Tal frase fue citada y celebrada, en 1969, por Álvaro Alsogaray, el economista y político de ideas liberalconservadoras a quien debemos, en Argentina, la difusión de la expresión "economía social de mercado". ${ }^{16}$ Fervoroso defensor de las virtudes del libre mercado, el ingeniero se encuentra relacionado con PRO, tanto en virtud del vínculo "pedagógico" que lo unió con Mauricio Macri cuando éste era un joven estudiante de ingeniería, como por el hecho de que una parte de los cuadros de PRO proceden de la UCEDE el partido que Alsogaray fundó en la década de 1980 (Vommaro, Morresi y Belloti, 2015; Arriondo, 2016).

Pero, además de ser recuperada por Alsogaray, la osada frase de Röpke también resonó, si bien de manera más ambigua, en el ámbito de la intelectualidad católico-democrática argentina.

Así, mientras hacia fines de la década de 1950, Iván Vila Echagüe (1960), uno de los fundadores del Partido Demócrata Cristiano argentino, se sirvió de los planteos de Röpke con la finalidad de "reconciliar" ciertos aspectos del capitalismo liberal con la doctrina social cristiana, no faltaron voces que, por la misma época, hicieron alusión a la formulación del intelectual alemán para sostener, en una dirección contraria, que el neoliberalismo permanecía aún "demasiado capitalista” (Criterio, 1959, p. 525).

Esta última crítica, esbozada desde la Argentina, no era una opinión aislada. Por el contrario, la mentada compatibilidad entre la "economía social de mercado" y la doctrina social de la Iglesia, proclamada por los neoliberales, fue puesta en discusión desde un punto de vista católico ya desde los primeros ensayos de la aplicación práctica de las ideas neoliberales en la Alemania de la Segunda Postguerra. 
Así, por ejemplo, entre los integrantes del Consejo Científico que entre 1948 y 1965 asesoró a Ludwig Erhard, estaba uno de los redactores de la encíclica Quadragesimo Anno, el filósofo jesuita Oswald von NellBreuning, quien en la fase inicial de implementación de la economía social de mercado se dirigió críticamente al neoliberalismo. La polémica entre el filósofo y algunos de los representantes del neoliberalismo giraba en torno al denominado principio regulador "auténtico": ¿era la "competencia” o la "justicia social”?

Una discusión que involucró aspectos semejantes se dio hacia fines de la década de 1940 en la Argentina, en el seno de la revista Orden Cristiano, a partir de la publicación del Manifiesto aprobado en la reunión de los líderes de las fracciones democristianas de Sudamérica que se realizó en 1947 en Montevideo, y en el que, entre otras cuestiones, se proclamaba el deseo de los democristianos de "superar el capitalismo (...) por medio del humanismo económico". Tal consigna disparó un debate -que otros de los autores que participan de este Dossier han estudiado en profundidad (Zanca, 2013; Vicente, 2015; Mauro y Vicente, 2017)-cuyos términos resultaban afines a la polémica que se había desarrollado al interior del Consejo científico que asesoró a Erhard, entre los intelectuales católicos y los neoliberales. Lo que se discutió en las páginas de Orden Cristiano fue la posibilidad de articular el mercado con los valores de la solidaridad y la equidad en un marco democrático.

Entre los argumentos que se pusieron a rodar en tal contexto, los intelectuales que en la Argentina comulgaban con las ideas de Jacques Maritain plantearon una serie de ideas que remitían a una tercera formulación histórica de la noción de "tercera vía". Para los "humanistas cristianos", la justicia social sólo podía conseguirse si se postulaba, de un modo explícito, como meta del sistema económico. Ello basculaba hacia un "reformismo" institucional (definido de un modo muy poco preciso) que apuntaba a la construcción de un "tercer modelo" alternativo al capitalismo y al comunismo. Al igual que el discurso de "tercera vía" que A. Giddens delineara para aggiornar la socialdemocracia británica y que el "tercer camino" preconizado por Röpke, en esta otra formulación el motivo de la "comunidad" ocupaba un papel relevante.

Ciertamente, los términos del debate en el que los humanistas cristianos pusieron en juego la idea de un "tercer modelo" diferían notablemente de aquellos a los que remite la misma expresión en las voces de los intelectuales que a lo largo de la década de 1990 se dieron por tarea "modernizar" la socialdemocracia; esto es, de las voces que funcionan, de manera explícita y deliberada, como un punto de apoyo para la construcción identitaria de PRO.

Pero la tensión entre el respeto al libre mercado y la implementación de medidas orientadas a atender a la cuestión social que interfieran con el principio de la competencia se hizo sentir, asimismo, en la construcción de PRO, partido que si bien se identifica con la defensa del libre mercado, atribuye un papel importante al valor de la solidaridad (Morresi, 2016) y cuenta con una dirigente de primera línea, Gabriela Michetti, que procede de las filas de la democracia cristiana, y con un núcleo de cuadros ideológicamente afines a las ideas del catolicismo social (Vommaro, 2016).

Por último, la decisión de incluir un cuarto grupo de debates en la historia abreviada de los modos de pensar la "tercera vía" que tracé en el artículo de referencia, grupo que incluye temas, desarrollos teóricos y utopías procedentes tanto de los discursos de Juan D. Perón, como de algunos intelectuales peronistas, se explica porque en el documento "La Vía PRO" Devoto (2014) advierte que el peronismo se había definido como una "tercera posición".

Adentrarme y perderme (hasta donde el tiempo acelerado del trabajo académico me lo permitió) en los términos específicos de los debates con los cuales se asoció, en diferentes períodos históricos, coyunturas, climas de ideas, la expresión "tercera vía” tuvo réditos, algunos esperados y otros inesperados.

Entre los primeros, anoto que el recorrido realizado me permitió afiliar el discurso de PRO en una trama más amplia y añosa de discursos que, desde vertientes político-ideológicas muy diversas (fascismo, neoliberalismo, humanismo cristiano, entre otras .), hicieron pensable el problema de la sostenibilidad social y humana del orden de mercado 
Por otro lado, el hecho de desplegar y superponer, como en un juego de naipes, los cuatro grupos de discusiones a los que antes me referí me condujo, de un modo que en ningún caso había previsto al inicio de la investigación, a (re)encontrar "cuestiones" de más larga duración que, como la pregunta por la "comunidad" o el problema ético del "justo medio", resuenan en las formulaciones, diversas, que ordoliberales, humanistas cristianos, cientistas sociales de centro e intelectuales peronistas dieron a la tercera vía.

\section{LA PROBLEMATIZACIÓN COMO FANTASÍA DE INTERFERENCIA}

Recapitulando: de la mano de ejercicios que dependen de la imaginación histórica, por medio de los cuales una práctica (problemática) del presente se vincula y compara con otras prácticas pasadas, que reconocen diversas cronologías, el método al que aquí me refiero busca demarcar una "problematización" que funciona como "unidad" del análisis socio-histórico a partir del cual la investigación se desarrolla.

Como consecuencia de la apertura hacia múltiples temporalidades, el problema que activa la indagación (así, en el ejemplo anterior, la fórmula de "tercera vía" tal como fue movilizada en la escena política argentina hace algunos años) pierde coherencia; se percibe, en cambio, como la combinación o anudamiento de elementos heterogéneos, algunos de los cuales proceden de otras elaboraciones, pasadas, de la misma fórmula.

El "motivo principal", "encuadre" o "pregunta amplia y persistente" que hace pensable, en la dispersión, ciertas encrucijadas, dificultades, sólo puede identificarse (o, en otros términos, "reencontrarse") con ayuda de la imaginación histórica.

Es preciso destacar que los ejercicios retrospectivos que se ensayan con la finalidad de que despunte una "problematización" involucran un rastrillaje "perspectivista" de la historia. En ese sentido cabe destacar que, al trazar sus afamadas genealogías, Foucault prestó atención a los momentos y lugares en los que detectó desplazamientos importantes en las prácticas (Bacchi, 2019, p. 182).

Bajo la mirada genealógica, la historia pasada se percibe bajo la forma de "piezas" (Michon, 2002) que pueden movilizarse ("reactivarse") en forma separada, unas de otras. Así, por ejemplo, en la historia de la tercera vía que propongo en el trabajo mencionado en el apartado anterior me detuve a considerar sólo algunos de los "focos" del debate en torno al problema de la sostenibilidad social y humana del orden de mercado. Pero quedaron afuera del análisis otros varios focos: las versiones de orientación corporativista (que oscilaban entre el autoritarismo y un modelo de democracia no liberal) plasmadas en las encíclicas Rerum Novarum (1890) y Quadragesimmo Anno (1931), el uso que en las décadas de 1920 y 1930 el fascismo italiano hizo del término "tercera vía" para designar un nuevomodelo civilizatorio alternativo al capitalismo y al comunismo, y todas aquellas estrategias y modelos que, entendiendo la tercera vía en términos de "economía mixta", se ensayaron a lo largo de la segunda mitad del siglo XX (tanto en algunas de las socialdemocracias europeas como en ciertos países del exbloque soviético) para administrar la economía nacional sobre la base de la combinación del principio del libre mercado y la planificación estatal.

Es la diferencia que separa el presente respecto del pasado lo que otorga al propio presente del investigador la autoridad de interpelar el pasado, para elegir de este último los elementos que sean estratégicamente importantes para movilizar, en esta "nuestra" actualidad (Lorenzini, 2018, p.3).

La cuestión de "qué" es lo que instiga el acto de problematizar es importante porque tiene que ver con el tipo de efecto crítico que se asocia con la metodología. Se ha insistido largamente en cuanto a que el blanco del enfoque son las asunciones "auto-evidentes" de una forma de vida dada y el carácter supuestamente natural, inevitable y único de lo dado (Geuss, 2002, p. 211).

Pero si, como señalamos en el punto 1, más que "cuestionar" lo que se desarrolla de manera "natural" y "a-problemática", el tipo de reconstrucción socio-histórica que promueve el trabajo con problematizaciones lo que hace es parasitar la "ocasión" en la que ciertos ámbitos de experiencia se vuelven problemáticos, el propósito de la crítica será "esclarecer" los términos de referencia en los que se enmarcan las preguntas y respuestas que suscita, en el presente, la pérdida de familiaridad o el incremento de dificultades en un cierto 
ámbito de experiencia. Y un impacto crítico de ese estilo se consigue comparando las condiciones que, en otros momentos y lugares de la historia pasada, posibilitaron el desarrollo de reflexiones en torno a la misma cuestión.

Así, cada uno de los cuatro grupos de discusiones en el marco de las cuales despuntaron diversas formulaciones de la "tercera vía" constituye una unidad discreta, tiene condiciones de producción específicas; una especificidad sincrónica que en ningún momento puede perderse de vista.

Cada uno constituye un "nodo" o "foco" de problematización independiente de los demás: en cada caso es posible distinguir y analizar el balance de relaciones de fuerza que permitió que se aceptaran e impusieran ciertas miradas sobre el problema en discusión y no otras; los saberes y discursos que hicieron pensable "lo tercero"; las circunstancias de geopolítica internacional, el clima de ideas, las instituciones en cuyo marco se produjeron las elaboraciones relativas a la tercera vía que procuré recuperar en el artículo antes mencionado.

Al poner a disposición, para el escrutinio crítico, las formas en que, en otras coyunturas, pasadas, se articuló una cuestión que sigue vigente, los términos en los que se desarrollan los debates sobre la historia presente se expanden. La reactivación de las historias pasadas y su comparación con la situación actual hacen que los límites que condicionan nuestras maneras actuales de ser, actuar y pensar se vuelvan conscientes (Koopman, 2009). Una cosa tal facilita la identificación de aquellos puntos débiles y líneas de fractura por donde es posible colar el pensamiento en orden a producir una diferencia (Rose, 1999, p. 277).

La historia que de tal modo resulta escrita es una historia fragmentada y discontinua, ${ }^{17}$ que se saltea, deliberadamente, la reposición de aquel saber destinado a informar sobre lo que, en términos de la acumulación de conocimientos y de las condiciones que posibilitan dicha acumulación, transcurre entre una y otra expresión histórica de la problematización bajo estudio.

El estudio socio-histórico de las problematizaciones conecta prácticas que reconocen temporalidades múltiples y discontinuas, y en ese movimiento suele dejar a la vista los "hiatos", las "lagunas" que se abren entre las diferentes "unidades" que se comparan. Más allá de la importancia que en tal aproximación se confiere a la especificidad sincrónica de cada uno de los "momentos" o "avatares" de una problematización, un tal efecto de impasse resulta del hecho de que, a diferencia de lo que sucede en el ámbito de la historia intelectual, en la cual la indagación de los mecanismos de transmisión de las ideas resulta una dimensión central e ineludible de la práctica. La pregunta relativa a los modos concretos, a través de los cuales las ideas / discursos / conceptos/ racionalidades, . "viajan" a través del tiempo no está, en principio, en el horizonte de análisis de los genealogistas; cuestión que, sin embargo, ha comenzado a revertirse en los últimos años.

Por otro lado, la falta de atención respecto de lo que "media" o "eslabona" un foco o punto de problematización con otros, anteriores y posteriores, puede generar una sensación de "desorden".

No obstante, el hecho de que las diferentes versiones de una misma problematización no se vinculen unas con otras según una forma "secuencial", posibilidad por la que, es menester aclarar, se han inclinado muy prestigiosos genealogistas (verbigracia, Castel, 1997; Rose, 1999), no implica que dichas versiones no puedan "disponerse" u "organizarse" conforme un patrón distinto de aquel de la "secuencia temporal" e, incluso, de la misma "secuencia".

El mismo Foucault se ha servido largamente de metáforas espaciales para aludir a la relación entre las unidades. Así, por ejemplo, al referirse al régimen de inteligibilidad de los dispositivos (y lo mismo cabe para las problematizaciones) apeló a la imagen de un "poliedro", formado por múltiples caras cuyo número no está definido de antemano y cuyo análisis nunca puede considerarse como plenamente terminado (Foucault, 2001). Y, mientras R. Castel (1997, p. 19) se refirió a la problematización como un "haz" unificado de interrogantes, N. Rose (1999, p. 12) propuso considerar los capítulos del libro que dedica a la genealogía del neoliberalismo (o, en sus palabras, del "liberalismo avanzado") como un "glosario parcial o una selección de entradas de una enciclopedia imaginaria y siempre inacabada".

Por otro lado, el hecho de que, en lugar de disimular los puntos de sutura, la historia de las problematizaciones los deje a la vista, tiene que ver con la "fantasía"18 de intervención que está asociada al 
método. Ella consiste, en términos de Foucault (1979), en producir una "interferencia" entre nuestra realidad (actual) y aquello que conocemos de nuestra historia pasada a partir de lo cual el vínculo con el presente resulte transformado.

\section{REFERENCIAS}

Aguilar, P., Glozman, M., Grondona, A. y Haidar, V. (2014). ¿Qué es un corpus? Entramados y Perspectivas, 4(4), pp. 35-64.

Alsogaray, A. (1968). Bases para la acción política futura. Buenos Aires: Atlántida.

Arriondo, L. (2016. De la UCeDe al PRO. Un recorrido por la trayectoria de los militantes de centro-derecha de la ciudad de Buenos Aires. En G. Vommaro, G. y S. Morresi. (Orgs.). Hagamos equipo. Pro y la construcción de la nueva derecha en Argentina (pp.203-215). Los Polvorines: UNGS.

Armitage, D. (2012). What's the Big Idea? Intellectual History and the Longue Durée. History of European Ideas, 38(4), 493-507.

Bacchi, C. (1999). Women, Policy and Politics. The Construction of Policy Problems. Londres: SAGE.

Bacchi, C. (2009). Analysing policy: What's the problem represented to be? Nueva Gales del Sur Pearson Education.

Bacchi, C. (2019). ¿Por qué estudiar las problematizaciones? Haciendo visible la política. En A. Avellaneda y G. Vega, G. (Dirs.), Conductas que importan (pp. 179-197). Corrientes: Eudene.

Barnett, C. (2015). On problematization, Nonsite.org. Recuperado de https://nonsite.org/article/on-problematizati on

Bialakowsky, A. (2018). Investigar teoría sociológica del Sur y del Norte: la propuesta del abordaje simultáneo, Perfiles Latinoamericanos, 52.

Castel, R. (1997). La metamorfosis de la cuestión social. Buenos Aires: Paidós.

Chao, D. (2019). El gobierno a través de las problematizaciones. Una lectura sobre Carol Bacchi. En J. Bartlett, y D. Chao (Comps.), El gobierno como problema (pp. 123-152). Corrientes: Universidad Nacional del Nordeste.

Criterio (1959). Tiempo, política y economía. Criterio, No 1336, 523-525.

Devoto, M. (2014). La Vía PRO. Una aproximación a lo que somos. Recuperado de http://cpcambio.com.ar/wp-co ntent/uploads/2015/01/LaViaPro.pdf.

Devoto, M. (2015). 19 Motivos. Ensayando el cambio politico. Buenos Aires: Planeta.

Fabian, J. (2014). Time and the Other. How Anthropology Makes Its Object. Nueva York: Columbia University Press.

Foucault, M. [1978] (2001). Table ronde du 20 mai 1978. En Autor Dits et écrits II. París: Gallimard.

Foucault, M. (1979). Foucault étudie la raison d' État, en Dits et écrits II (pp. 801-805). París: Gallimard.

Foucault, M. [1984] (1999). Polémica, política y problematizaciones. En Autor. Estética, ética y hermenéutica. Obras Esenciales. Volumen III (pp. 353-361). Barcelona: Paidós.

Garland, D. (2014). What is a 'history of the present'? On Foucault's genealogies and their critical preconditions. Punishment \& Society, 16(4), 365-384.

Gerbaudo, A. (agosto, 2013). Las voces de un "archivo": Notas a propósito de las clases de los críticos en la universidad de la posdictadura (1984-1986). VI Jornadas de Filología y Lingüística, 7 al 9 de agosto de 2013, La Plata, Argentina. Recuperado de http://www.memoria.fahce.unlp.edu.ar/traba_eventos/ev.3856/ev.3856.pdf.

Geuss, R. (2002). Genealogy as critique. European Journal of Philosophy, 10(2).

Giddens, A. (1999). La tercera vía. Madrid: Taurus.

Grondona, A. (2018). El debate Natanson. Una reseña culpable. El búho y la alondra, Enero / Junio 2018, N Ciclos y viceversa.

Haidar, V. (2005). La problematización de la cuestión de los riesgos laborales por los reformistas liberales: las contribuciones de Bialet Massé, Storni y Alsina. Cuartas Jornadas de Sociología de la Universidad Nacional de La 
Plata, Facultad de Humanidades y Ciencias de la Educación de la Universidad Nacional de la Plata. CD-ROM ISSN 1850-2458.

Haidar, V. (2011). Hacer vivir, hacer producir: Racionalidades y tecnologías para el gobierno de la salud y la enfermedad laboral (Argentina, 1995-2007) (Tesis de Doctorado en Ciencias Sociales, inédita). Facultad de Ciencias Sociales, Universidad de Buenos Aires. Buenos Aires.

Haidar, V. (2013). La historia como condición para la inteligibilidad del presente: una aproximación desde la sociología de las problematizaciones. XIV Jornadas de Interescuelas/Departamentos de Historia. Facultad de Filosofía y Letras de la Universidad Nacional de Cuyo. Mendoza Recuperado de: https://www.aacademica.org/000-010/ 946

Haidar, V. (2018). La problematización ordoliberal de "lo social". Tabula Rasa, № 28, pp. 275-296.

Haidar, V. (2019). Entre la formulación de problematizaciones y la organización de corpus: herramientas para escribir las historias del presente. En P. de Marinis (Coord.). Exploraciones en teoria social. Ensayos de imaginación metodológica (pp. 269-304). Buenos Aires: IIGG-Clacso.

Haidar, V. (2020). La Vía PRO como “tercera vía”. Estudios Sociales, 58(1), 207-230.

Jay, M. (2017). “Hey! What's the Big Idea?”: Rumiations on the Question of Scale in Intellectual History. New Literary History, 48(4), 617-631.

Lorenzini, D. (2018). Benjamin/Foucault: histoire, discontinuité, utopie. Phantasia, N 7, 1-10.

Mauro, D. y Vicente, M. (2017). Un camino resbaladizo. Los católicos antifascistas ante la cuestión social en Argentina: los casos de I Popolari y Orden Cristiano en las décadas de 1930 y 1940. En M. Tenti (Comp.). Iglesia y religiosidades (pp.191-207). Rosario: Prohistoria Ediciones.

Michon, P. (2002). Strata, Blocks, Pieces, Spirals, Elastics and Verticals. Six figures of time in Michel Foucault. Time \& Society, 11(2/3), 163-192.

Morresi, S. (2011). Las raíces del neoliberalismo argentino (1930-1985). M. A. Rossiy A. López (Comps.). Crisis y metamorfosis del Estado argentino: el paradigma neoliberal en los noventa (pp.47-69). Buenos Aires: Luxemburg.

Morresi, S. (2016). Acá somos todos democráticos. El PRO y las relaciones entre la derecha y la democracia en Argentina. En G. Vommaro y S. Morresi (Orgs.). Hagamos equipo. Pro y la construcción de la nueva derecha en Argentina (163-201). Los Polvorines: Universidad Nacional de General Sarmiento.

Osborne, T. (2003). What is a problem? History of the human sciences, 16(4), 1-17.

Rose, N. (1999). Powers offreedom. Reframing political thought. Cambridge: Cambridge University Press.

Restrepo, E. (2008). Cuestiones de método: “eventualización” y problematización en Foucault. Tabula Rasa, N 8, 111-132.

Revel, J. (2007). Michel Foucault: discontinuité de la pensé ou pensée du discontinu?, Le Portique, N 13-14, 1-11.

Röpke, W. [1942] (1956). La crisis social de nuestro tiempo. Madrid: Biblioteca de Ciencia Económica.

Röpke, W. (1949). Civitas Humana. Madrid: Revista de Occidente.

Tarde, G. [1895] (2011). Las leyes de la imitación y la sociología. Madrid: Centro de Investigaciones Sociológicas.

Vicente, M. (2015). La cuestión del liberalismo en Orden Cristiano: entre las posiciones antifascistas y la problemática identitaria (1941-1948). Pasado Abierto, № 2, 242-264.

Vila Echagüe, I. (1960). Cuestiones disputadas en la democracia cristiana. Buenos Aires: Atlántico.

Vommaro, G. (2016). Contribución a una sociología política de los partidos. Los mundos sociales de pertenencia y las generaciones políticas de PRO. En G. Vommaro y S. Morresi (Orgs.). Hagamos equipo. Pro y la construcción de la nueva derech a en Argentina (pp.111-161). Los Polvorines: UNGS.

Vommaro, G. (2017). La larga marcha de Cambiemos. Buenos Aires: Siglo XXI.

Vommaro, G., Morresi, S. y Belloti, A. (Eds.) (2015). Mundo Pro: anatomía de un partido fabricado para ganar. Buenos Aires: Planeta.

Zanca, J. (2013). Cristianos antifascistas. Conflictos en la cultura católica argentina. Buenos Aires: Siglo XXI. 


\section{NOTAS}

1 Dejando a un lado las coordenadas metodológicas que introduje en mi tesis de Doctorado (Haidar, 2011), como las referencias a la noción de "problematización” que incluí en un artículo de autoría colectiva en el que se discute la noción de "corpus", tal como se emplea en el ámbito de las ciencias sociales (Aguilar, Glozman, Grondona y Haidar, 2014), el texto en el que de manera más sistemática me referí a la metodología que orienta mis investigaciones es el capítulo que escribí para el libro Ensayos de imaginación metodológica (Haidar, 2019), que coordina Pablo de Marinis.

2 La primera vez que me referí, frente a una audiencia constituida tanto por historiadores como por cientistas sociales, al modo en que me serví de la noción de "problematización” para dar cuenta de la emergencia, en la Argentina, del primer régimen estatal de protección frente a los accidentes y enfermedades causadas por el trabajo fue en una ponencia que presenté en las IV Jornadas de Sociología de la Universidad Nacional de La Plata (Haidar, 2005). Repetí la experiencia, frente a un público formado sólo por historiadores, en una mesa que, en el marco de las XIV Jornadas de las Interescuelas de Historia, proponía un diálogo entre teoría social e historiografía (Haidar, 2013).

3 En la "eventualización" de la "actualidad" en la que se encuentran inmersos investigadoras e investigadores, y cuyo carácter "problemático" activa el trabajo de interrogación, reside el efecto crítico del enfoque que aquí discutimos. Como señala Restrepo (2008), la "eventualización” es la estrategia que nos permite tomar distancia de lo que nos parece evidente, de la tendencia a subsumir el acontecimiento (la "singularidad", agregamos nosotros, del presente) en horizontes de inteligibilidad o unidades predeterminadas.

4 Me refiero a la encuesta, transcripta en la presentación del Dossier, a partir de la cual se organizó la "Conversación sobre los usos de la historia para investigar problemas sociales" a la que se vinculan éste y los demás escritos que lo componen.

5 Ello es así porque, más que expositora, en la referida Conversación oficiaba yo como organizadora y coordinadora.

6 "El trabajo de una historia del pensamiento seria reencontrar [el subrayado es mío] en la raíz de estas diversas soluciones la forma general de problematización que las ha tornado posibles - hasta en su oposición misma-; o, más aun, lo que ha hecho posibles las transformaciones de las dificultades y obstáculos de una práctica en un problema general para el que se proponen diversas soluciones prácticas" (Foucault, 1999, p.159).

7 Diccionario etimológico en línea, http://etimologias.dechile.net/?cuestio.n

8 Armitage (2012, p. 497) utiliza la expresión "gran idea" como rúbrica del "reencuentro" de la historia intelectual con la perspectiva de la longue durée. Este se habría verificado, en la opinión del autor, en un conjunto de trabajos provenientes del mundo anglosajón que comparten la ambición de construir historias diacrónicas e interdisciplinarias (al menos en el sentido en que laboran con diferentes géneros de la producción intelectual), focalizadas en torno de aquellos “conceptos centrales" de los vocabularios políticos, éticos y científicos del mundo anglosajón o europeo, que tienen "pasados profundos" y cuya valoración ha cambiado, en forma decisiva, en algún momento en los últimos trescientos años. Partiendo de la actitud de "sospecha" e, incluso, de la "ironía” que en el habla coloquial de los Estados Unidos están asociadas a la expresión "Hey! What's the Big Idea?”, Martin Jay (2017) se ocupa de explorar algunas de las limitaciones del celebrado revival de la longue durée en el ámbito de la historia intelectual.

9 Para caracterizar el tipo de interrogaciones pertinentes para el desarrollo de sus afamadas investigaciones genealógicas o historias filosóficas, Michel Foucault utiliza el adjetivo "general”. Así, conforme el modo de pensar del autor, una problematización es una "forma general" o una "interrogación general”. Consciente de las resonancias que en el ámbito de la filosofía tiene el término "general", me inclino por utilizar otros vocablos y expresiones (como "suficientemente amplia”) para calificar la escala que considero adecuada al estudio de problematizaciones.

10 La relación que Foucault establece entre una problematización (en tanto "modo" o "estilo" de pensamiento) y la actualidad (que establece los límites de lo que puede pensarse) deja abierta la pregunta por la temporalidad de lo que, contando como pensamiento, escapa, en el momento en que se produce, a los marcos de referencia de una determinada cuestión. Estudioso del fenómeno del "público", Gabriel Tarde era muy consciente de la coerción que las "cuestiones" ejercían en relación con la producción de auténticas novedades. Aun así, en su modo de entender lo social hay lugar para el pensamiento que sucede por fuera de los carriles de lo que la cuestión impone: "Sólo algunos espíritus salvajes, ajenos bajo su campana de buzo al tumulto de la superficie del océano social en que están sumergidos, rumian acá y acullá problemas raros, absolutamente desprovistos de actualidad. Estos son los inventores de mañana” (Tarde [1895], 2011, p. 128).

11 Tal es el título de un artículo de mi autoría publicado, recientemente, en la revista Estudios Sociales (Haidar, 2020).

12 Para una reconstrucción de ese debate véase el artículo de Ana Grondona (2018) "El debate Natanson. Una reseña culpable".

13 Es menester señalar que la discusión a la que me refiero corrió por carriles separados a las elaboraciones y debates que, en torno a la cuestión de la identidad político-ideológica de PRO, ya habían planteado Sergio Morresi (2016) y Gabriel Vommaro $(2015,2017)$, ciertamente en libros dedicados, principalmente, a un público universitario. 
14 La elaboración de este último documento se corresponde con una iniciativa de «Compromiso para el cambio» (CPC), uno de los grupos internos del partido al cual pertenece su autor, Mauricio Devoto (Haidar, 2020).

15 Devoto no aporta datos que permitan referenciar de forma precisa al autor de dicha expresión, sino que para introducirla se sirve del discurso referido, indicando que había sido pronunciada por un "presidente latinoamericano". Se trataba del expresidente de Colombia, Juan Manuel Santos.

16 Admirador de Erhard, Alsogaray se sirvió de aquella fórmula para designar su propio programa político-económico, cuyos lineamientos aparecen condensados en su libro Bases para la acción política futura (1968).

17 El énfasis en pensar y escribir la historia desde la perspectiva de las "discontinuidades" y no de las continuidades que caracteriza la obra de Foucault, como muchos intérpretes han señalado (Michon, 2002; Revel, 2007), reconoce tres grandes inspiraciones: la literatura (el grupo Tel Quel pero también Julio Verne), la tradición de la historia de la ciencia (Bachelard, Canguilhem, entre otros) y la escuela de los Anales.

18 Tomo prestado de Analía Gerbaudo (2013) el uso del término "fantasía" para atenuar la posible connotación redentorista implicada en el propósito que el mismo Foucault (1979) atribuye a sus libros: "provocar una interferencia" que produzca efectos reales sobre nuestra historia presente. 